\title{
Los Coloquios Latinoamericanos de Fotografía y la reconfiguración de las prácticas fotográficas
}

\author{
The Latin American Colloquiums of Photography and the \\ reconfiguration of photographic practices
}

\author{
https://doi.org/10.22235/d.vi32.2108 \\ Leticia Rigat \\ Universidad Nacional de Rosario, Rosario, Argentina \\ Consejo Nacional de Investigaciones Científicas y Técnicas (CONICET), Argentina
}

ORCID: 0000-0002-4761-7142

\begin{abstract}
RESUMEN
El presente trabajo se propone reflexionar sobre los cambios en los modos de representación en la fotografía latinoamericana en los años noventa. En ese período es posible observar una ruptura con el fotodocumentalismo de registro directo, estética que se había establecido como característica de la fotografía de la región en las décadas precedentes. Dicha transformación es observable a partir del auge de obras fotográficas caracterizadas por la intervención de los autores -ya sea sobre el plano de la representación o sobre el plano de lo representado-, lo que genera una dimensión de la temporalidad propia del arte contemporáneo y del pensamiento latinoamericanista: deconstruir las imágenes que conformaron los imaginarios y la identidad latinoamericana en el presente. En este sentido, se indagan los documentos y actas de los Coloquios Latinoamericanos de Fotografía que tuvieron lugar entre los años 1978 y 1996, en los que se buscó definir y categorizar a las prácticas fotográficas.
\end{abstract}

Palabras clave: fotografía; Latinoamérica; documentalismo; identidad; arte contemporáneo.

\begin{abstract}
This article reflects on the changes in the ways of representation in Latin American photography during the 1990s. In this period, it is possible to observe a rupture with the documentary photography of direct registration, a kind of aesthetics that had been established as a feature of the regional photography in the preceding decades. The above-mentioned transformation can be observed from the rise of photographic works characterized by the authors' intervention (eitheron the level of representation and/or the level of the represented), causing a dimension of temporality typical of contemporary art and the Latin Americanist thought: to deconstruct the images that shaped our imaginaries and the Latin American identity in the present. In this sense, the documents and minutes from the Latin American Colloquiums of Photography, which took place between 1978 and 1996, are inquired. During these colloquiums, photographic practices tried to be defined and categorized.
\end{abstract}

Keywords: photography; Latin America; documentary; identity; contemporary art. 
$1::$ La historia oficial de la fotografía se ha centrado en el detalle de los avances técnicos realizados en los paises centrales, y a partir de fotógrafos europeos y estadounidenses. No obstante, a partir de los años 70, en Latinoamérica se buscó reconstruir una historia que incluyera a los pioneros de la invención de la fotografía y a los fotógrafos oriundos de la región. Entre ellos se destaca la labor de Kossoy (2001).

\section{Introducción}

El propósito de este trabajo es reflexionar sobre los cambios en los modos de representación en la fotografía latinoamericana en la década del noventa. Es posible observar en este período una transformación en las prácticas fotográficas respecto a la estética que se había establecido como característica en la región en las décadas precedentes: el fotodocumentalismo de registro directo.

Desde esta perspectiva, se busca explorar, a partir de una lectura crítico-interpretativa, diferentes teorías a través de las cuales académicos, críticos, fotógrafos y curadores buscaron definir a la fotografía latinoamericana. A tal fin se toman como eje los Coloquios Latinoamericanos de Fotografía que tuvieron lugar entre los años 1978 y 1996, en los que se buscó caracterizar a la fotografía de la región. Se indaga en los documentos y las actas de estos coloquios con el objetivo de proporcionar una lectura sobre el pensamiento sobre la fotografía latinoamericana en aquel contexto, intentando identificar los principales ejes de discusión.

Dicho análisis se propone a partir de la comparación de dos momentos diferentes. Por una parte, los primeros coloquios latinoamericanos de fotografía, en los que se comenzó a debatir sobre qué caracteriza a la fotografía latinoamericana. Fue a partir de estos que se estableció una categoría que englobaba a las prácticas fotográficas bajo la lógica del documentalismo para la representación del ser latinoamericano, su identidad y su historia compartida en las diferentes naciones. Por otra parte, el cambio de dicha definición en la década del noventa, momento en el que puede observarse una transformación en los modos de pensar a la fotografía realizada en América Latina. Esto dio lugar a una renovación de los modos de representación a través de la imagen fotográfica, con lo que se buscaba complejizar las miradas sobre el pasado colonial, el pasado reciente, la heterogeneidad de nuestras identidades y las diversidades culturales.
En este sentido, en los años noventa es posible identificar un conjunto de obras fotográficas que rompen con la concepción ontológica que había marcado el valor de lo documental, caracterizadas por la intervención de los autores -ya sea sobre el plano de la representación o sobre el plano de lo representado-, generando una dimensión de la temporalidad propia del arte contemporáneo: recuperar el pasado, deconstruir las imágenes que conformaron nuestros imaginarios, indagar la memoria y la identidad latinoamericana en el presente, a partir de operaciones artísticas como el collage, la puesta en escena, la resignificación y alteración de archivos.

\section{Hacia una definición de la fotografía latinoamericana}

Los estudios sobre fotografía latinoamericana son relativamente recientes. No fue hasta la década de 1970 que comienzan a aparecer trabajos de investigación, coloquios y exhibiciones que ponen en escena este concepto. Desde aquel momento al presente, las investigaciones en el tema, las exposiciones, coloquios, bienales y debates se han incrementado notablemente, $\mathrm{y}$ han ido variando determinados enfoques en torno a la fotografía y a Latinoamérica. De los primeros casos, se puede decir que en su mayoría se trataba de investigadores europeos o norteamericanos que reproducian los ejes verticales de los centros a las periferias (Sampaio Barbosa, 2011; Zerwes, 2016; Cisneros Hernández, 2013) y en función de tópicos como lo exótico, lo tercermundista, el subdesarrollo y la violencia. ${ }^{1}$

El uso de la denominación fotografía latinoamericana tiene como antecedente, en primer lugar, un artículo de la investigadora venezolana María Teresa Boulton, publicado en 1950 en la Revista Reflejoseditada por el Club Fotográfico de Venezuela, bajo la dirección de José M. Gil Espinoza y Ángel J. Álvarez-(Villares Ferrer, 2016, p. 1). En segundo lugar, la Primera Exposición de Fotografía Latinoamericana 
(1949), organizada por la Unidad de Artes Visuales de la Organización de Estados Americanos (OEA), curada por el crítico de arte cubano José Gómez Sicre (Navarrete, 2017, p. 200). ${ }^{2}$ Son dos experiencias tempranas en la conformación de un imaginario en torno a la fotografía latinoamericana, pero en las que no se hicieron pronunciamientos específicos sobre qué caracteriza o define a las prácticas fotográficas de la región.

Es en la década del setenta cuando comienzan los estudios sistemáticos de las historias nacionales de la fotografía latinoamericana (Sampaio Barbosa, 2011; Zerwes, 2016), en conjunción a la emergencia de un "movimiento fotográfico latinoamericano" (Navarrete, 2017, p. 201) que cobró visibilidad en 1978 con la realización en México del Primer Coloquio Latinoamericano de Fotografía. Fue un momento inaugural en la definición de la fotografía latinoamericana (Navarrete, 2017; González Flores, 2005; Villares Ferrer, 2016; Carreras, 2018; Martínez, 2008;Corp, 2018; Cisneros Hernández, 2013) que tuvo su continuación en sucesivos encuentros: Segundo Coloquio Latinoamericano de Fotografía (México, 1981); Tercer Coloquio Latinoamericano de Fotografía (La Habana, 1984); Encuentro de Fotografía Latinoamericana (Caracas, 1993) y el V Coloquio Latinoamericano de Fotografía (México, 1996). ${ }^{3}$ Asimismo, luego del Primer Coloquio se impulsó la profesionalización e institucionalización de la fotografía en América Latina (Zewers y Costa, 2017).

Los mencionados coloquios se propusieron situar a la fotografía latinoamericana en el contexto de las actividades de la fotografía internacional, ${ }^{4}$ y propiciar una reflexión crítica sobre la identidad visual de las prácticas fotográficas de la región más allá de una distinción en términos geográficos (Carreras, 2018; Corp, 2018), identificando puntos en común en las producciones de los distintos países.
En 1978 se celebra en México el Primer Coloquio Latinoamericano de Fotografía, organizado por el Consejo Mexicano de Fotografía y con los auspicios del Instituto Nacional de Bellas Artes y la Secretaría de Educación Pública. Conjuntamente se realizó la exhibición Hecho en Latinoamérica en el Museo de Arte Moderno de México D.F., entre el 11 de mayo y el 9 de julio. ${ }^{5}$ En la presentación, la crítica de arte Raquel Tibol propone al documentalismo como práctica por excelencia de la fotografía:

La fotografía, por el hecho mismo de que sólo puede ser producida en el presente y basándose en lo que se tiene objetivamente frente a la cámara se impone como el medio más satisfactorio de registrar la vida objetiva de todas sus manifestaciones; de ahí su valor documental (Tibol, 1978, p. 19).

Tibol convoca a los fotógrafos de la región al encuentro y al diálogo, para que con "elocuencia crítica" contribuyan a expresar el ser latinoamericano, definiendo en los siguientes términos lo que considera "la plataforma común del fotógrafo latinoamericano": atareado con frecuencia en asuntos nacionales marcados por presiones económicas, políticas y militares, las dependencias del imperialismo y de la explotación oligárquica en la que vive la gran mayoría de los países de la región (Tibol, 1978, p. 20).

Pedro Meyer, presidente en aquel momento del Consejo Mexicano de Fotografía y una figura clave en la organización de casi todos los encuentros de esta época, afirmaba en su ponencia:

No quisiera dar la impresión de que la única fotografía que vale sea la llamada de denuncia social; pero si el fotógrafo escoge cualquier otra forma de manifestar su creatividad, de todas maneras tendrá que partir de la ineludible condición de
2:: Se presentó en la Galería de la Unión Panamericana, en Washington, del 12 de enero al 15 de febrero de 1949. Incluyó a los siguientes fotógrafos: Alfredo Linares (Bolivia); Esteban A. De Varona (Costa Rica); Julio Zadik (Guatemala); Luis Márquez, Agustín Mayo, Pedro Camps, Jesús M. Talavera, Raúl Conde, Lola Álvarez Bravo y Marianne (México); Federico Donna y A. Friedics (Paraguay); Martín Chambi, Rómulo M. Sassarego, González Salazar, Abraham Guillén y J. De Ridder (Perú); y Alfredo Boulton (Venezuela).

3:: Estos primeros encuentros pueden considerarse precursores de reuniones, coloquios y exhibiciones sobre fotografía latinoamericana que continúan hasta hoy: Ias Bienales organizadas por el Centro de la Imagen de México (desde 1980); el Forum de Fotografía Latinoamericana de Itaú Cultura (Brasil, 2007, 2010, 2013, 2016), las Jornadas de Fotografía en el Centro de Fotografía de Montevideo, Uruguay (desde 2005) y el Coloquio Latinoamericano de Fotografía de la Fundación Pedro Meyer, entre otros.

4:: La exposición fue considerada por Time-Life como una de las más importantes de 1978; recibió críticas positivas en la Revista Afterimage y en El Correo Catalán. Parte de sus obras se incorporaron a una exposición itinerante en los festivales de Venecia y Arles, en el Centro Internacional de Fotografía de Nueva York y en la muestra $L a$ fotografía latinoamericana contemporánea, organizada por el Museo de Arte Moderno de Paris (Santos, 2014, p. 166).

5:: Ambos eventos contaron con una amplia participación de fotógrafos y ponentes de distintos países, con 3098 fotografías de 355 fotógrafos de Argentina, Brasil, Chile, Paraguay, Colombia, Cuba, Ecuador, Estados Unidos, Guatemala, México, Panamá, Perú, Puerto Rico, Uruguay y Venezuela. 
6:: El comité de selección estuvo integrado por Néstor García Canclini (Argentina); Max Kozloff (Estados Unidos); Hérctor Méndez Caratini (Puerto Rico); Antonio Rodriguez (México); Maria Eugenia Haya (Cuba); Paul Leduc (México); y Pablo Ortiz Monasterio (México).

7:: Se recibieron 3126 imágenes de 512 autores de 21 paises. Los miembros del comité de selección fueron Raúl Corrales (Cuba), José Antonio Figueroa (Cuba), Fernell Franco (Colombia), Graciela Iturbide (México), Juca Martins (Brasil), Vladimir Sersa (Venezuela) y Jorge Timossi (Argentina). El encuentro contó con la participación de Fidel Castro, quien destacó a los coloquios como constructores de la unión latinoamericana. Su intervención es comentada en algunos documentos, pero no se ha encontrado su transcripción completa (Carreras, 2018, p. 23). la fotografía, es decir, de una realidad de la cual tomar sus imágenes $\mathrm{y}$, a diferencia del pintor que puede inventar sus realidades, el fotógrafo tiene que entrar en contacto con su mundo y seleccionar de allí lo que desea. Si aquí es donde escogimos producir, de América Latina, de las entrañas de estas tierras tendrá que surgir las imágenes que habremos de realizar (Meyeren Carreras, 2018, p. 17).

Se trata de un espíritu expuesto en diferentes ponencias, pero que puede reconocerse también en las notas que los fotógrafos enviaron para explicar su labor y los fundamentos de sus obras. Estas notas han sido incluidas junto a las fotografías que integraron la muestra en la publicación de las memorias del Primer Coloquio Latinoamericano de Fotografía, bajo el título Hecho en Latinoamérica (Consejo Mexicano de Fotografía, 1978).

En las afirmaciones de los fotógrafos puede notarse una constante reivindicación de las cualidades de la fotografía para la representación fiel de lo real, de sus posibilidades técnicas de registro directo, que lleva a una reafirmación de la fotografía como documento de denuncia de la situación social latinoamericana en cuanto a choques de culturas, violencias, pobreza y marginación.

En 1981, nuevamente en México, tuvo lugar el Segundo Coloquio Latinoamericano de Fotografía, organizado por el Consejo Mexicano de Fotografía y el Instituto Nacional de Bellas Artes. En términos generales, las bases de la convocatoria y de la selección de imágenes para la exposición Hecho en Latinoamérica ${ }^{6}$ en el Palacio de Bellas Artes de México D.F. fueron las mismas que en el Primer Coloquio.

En esta ocasión, Pedro Meyer volvía a destacar a la fotografía documental como la expresión por excelencia de la fotografía en América Latina, y a la identidad latinoamericana en relación con la colonización, las dependencias y los sometimientos de la región por el imperialismo. Proponiendo una reflexión sobre desde dónde miramos y pensamos a Latinoamérica, Meyer plantea una serie de interrogantes, a los que las distintas ponencias y diálogos buscaron dar respuesta: ¿Para quién y en dónde estamos fotografiando? ¿Cuáles son los parámetros para valorar nuestras obras? ¿A quiénes y dentro de cuáles contextos interesa mostrar la obra? ¿Cuáles son los mecanismos más idóneos para difundir la obra fotográfica nuestra? (Meyer, 1981).

Al igual que en el encuentro de 1978, la práctica documental es reivindicada como un medio de producir testimonios visuales y generar conciencia social (Villareal, 1981; García Joya, 1981; Günter, 1981). No obstante, se refuerza la cuestión de lo ideológico, de las codificaciones culturales del sentido donde el fotógrafo debe asumir una actitud crítica y comprometida con los propios actores sociales, con conciencia plena de las situaciones a fin de no reforzar ni reproducir estereotipos; todo con el objetivo de encontrar una mirada latinoamericana que permita la liberación del colonialismo cultural (García Canclini, 1981; Rosler, 1981; Grobet, 1981; Monsivais, 1981; Facio, 1981; Benedetti, 1981).

Tres años después, en 1984, se llevó a cabo el Tercer Coloquio Latinoamericano de Fotografía, esta vez en la Casa de las Américas de Cuba, junto con la tercera exposición Hecho en Latinoamérica. ${ }^{7}$ Tanto en la muestra fotográfica como en las exposiciones teóricas continúa predominando la reivindicación del documentalismo (Tibol, 1984/2018; Meyer, 1984/2018; García Canclini, 1984/2018). No obstante, comienza a hacerse notar un interés por explorar nuevos géneros, temas y formatos. En las exposiciones se señala la necesidad de una revisión historiográfica sobre la fotografía latinoamericana por fuera de las historias universales de fotografía y su visión eurocéntrica (Haya, 1984/2018), como así también de la creación de espacios de formación y exhibición. 
En este Tercer Coloquio se abandona el interrogante y se afirma la existencia de una fotografía latinoamericana cuyas prácticas tienen una historia, una estética y una función social propia. Las ponencias proponían una revisión y una ampliación de los debates de los coloquios precedentes y, en las conclusiones del encuentro, se planteaba la importancia de continuar con los coloquios y se proponía como sede a Brasil. Sin embargo, el Cuarto Coloquio no se realizaría hasta 1993, en Caracas. Además, se proponian varias exposiciones internacionales que no se realizaron hasta que, en 1992, se presentó Image and Memory, organizada por Fotofest en Houston (Carreras, 2018).

En 1993 se realizó en Caracas el Encuentro de Fotografía Latinoamericana, organizado y patrocinado por el Consejo Nacional de la Cultura de Venezuela y Fundarte. La muestra de fotografías Romper los márgenes estuvo curada por José Antonio Navarrete. Este encuentro buscaba dar continuidad a los coloquios precedentes; de hecho, fue considerado luego como el IV Coloquio Latinoamericano de Fotografía por los organizadores. No obstante, en este encuentro es posible notar una ruptura con los paradigmas establecidos en los coloquios anteriores en torno a la producción fotográfica de la región. Se daba mayor lugar a las producciones más conceptuales antes que al documentalismo, al valor testimonial y al posicionamiento ideológico. En la presentación, Ildemaro Torres (1993) planteaba la diferencia entre los tres primeros coloquios y el encuentro de 1993:

Se trata de recordar valiosas experiencias previas como las de los Coloquios de Fotografía celebrados en México y en la Habana, pero no necesariamente de retomarlas de donde ellas habian quedado, de valorar lo hecho como una guía para la planificación, pero con el cuidado de llevar adelante el nuevo compromiso a la luz de criterios de hoy (p. 3).
En su participación, Nelson Herrera Ysla (1993) proponía algunos interrogantes que ponían en duda la existencia de una fotografía latinoamericana:

La fotografía latinoamericana actual es también un enunciado ambiguo y un tanto resbaloso: ¿de cuál Latinoamérica estamos hablando? [...] ¿De qué fotografía, la que interpreta o experimenta? ¿o la que sirve para difundir la mentira del subdesarrollo en bellísimas páginas de revistas o periódicos y vallas urbanas? (p. 11).

Reforzando esta idea, Mariana Figarella (1993) en su comentario a la ponencia de Herrera Ysla, plantea las limitaciones de las prácticas fotográficas desde los paradigmas establecidos en los coloquios anteriores:

En la década pasada el panorama de la fotografía en el continente toma un nuevo giro, da una vuelta de tuerca: la concepción de la fotografía como instrumento para armar a partir de la realidad un discurso político social aminora, mas no desaparece para dar paso a propuestas más individualistas, intimistas y escépticas [...] Conceptos como puesta en escena, apropiación, reciclaje, descontextualización, deconstrucción ganan terreno dentro del nuevo lenguaje de la fotografía contemporánea latinoamericana (p.24).

Estos cuestionamientos y nuevos ejes de discusión se mantuvieron y ganaron fuerza en el V Coloquio Latinoamericano de Fotografía en 1996, organizado por El Centro de la Imagen de México y el Consejo Nacional para la Cultura y las Artes, y cuya sede volvía a ser México. Desde las presentaciones se convocaba a retomar aquellas inquietudes que se habían presentado en el Primer Coloquio de 1978 y a revisar cuáles habían sido los discursos y discusiones que sustentaron el pensamiento sobre la fotografía latinoamericana. 
De esta manera, Patricia Mendoza (1996/2000), en ese entonces directora del Centro de la Imagen de México, se refería a los objetivos del V Coloquio:

Discutir sobre el SER latinoamericano, [...] preguntarnos si un concepto geográfico define la mirada o si genera una entidad; si las circunstancias históricas que nos unen o el lenguaje común marcan una importancia en la forma de ver, gestando un sueño casi bolivariano traducido a la mirada, o si lo que importa ahora es conciencia ética de su acción transformadora (p. 9).

Además de una gran muestra fotográfica, el encuentro contó con la lectura de dos ponencias magistrales, que tematizaron desde un punto de vista histórico y teórico a la fotografía. Además se realizaron mesas centrales en las que se buscó profundizar la reflexión en torno a los usos de la imagen fotográfica.

La primera de las ponencias magistrales, titulada Tres carabelas rumbo al próximo milenio, estuvo a cargo de Pedro Meyer. En ella, Meyer reconoce que desde aquel Primer Coloquio de Fotografía de 1978 se habían producido profundos cambios, tanto en la fotografía como en América Latina. Haciendo referencia a la globalización, con sus grandes y aceleradas migraciones, como así también a los cambios en las tecnologías y las comunicaciones con la digitalización, propone una serie de interrogantes:

Si hablamos de fotografía latinoamericana, ¿a cuál fotografía nos estaremos refiriendo?, ¿a la que se origina en determinado territorio?, ¿a la que se crea a partir de cierta sensibilidad y herencia cultural?, ¿a la que solo retrata las caras de América Latina? Mi pregunta sería: ¿Qué condición debe reunir una obra para adquirir la carta de ciudadanía latinoamericana? (Meyer, 1996/2000, p. 17).
Meyer genera con ello un desplazamiento de sus propias intervenciones en los coloquios anteriores en cuanto a la búsqueda de una definición homogénea y abarcadora de la fotografía latinoamericana, para pensar ahora no ya en términos geográficos y situados, sino en el nuevo contexto mundial de globalización. Sobre este punto afirma:

[La fotografía latinoamericana] ha perdido esa nitidez conceptual con la que originalmente la habíamos trazado. Pienso que a medida que pasa el tiempo tendremos que ir encontrando nuevas fórmulas que presenten el tema de la identidad de manera más actual. Tendremos que ampliar el espacio que da cabida a lo que consideramos latinoamericano y al mismo tiempo responder a las necesidades particulares de identidad que se presentan distintas para cada individuo y para cada región (Meyer, 1996/2000, p. 17).

En cuanto a los cambios en la fotografía, auspicia que las nuevas tecnologías pueden colaborar en ampliar el espacio de circulación de la fotografía latinoamericana. Así también se desplaza de la idea del documentalismo como medio de registrar fielmente lo real para reivindicar otras prácticas fotográficas en las que se muestren las ficciones de lo real y de las imágenes. Desde esta misma perspectiva, y en la segunda conferencia magistral titulada El elogio del vampiro, Joan Fontcuberta (1996/2000) expone sobre la necesidad de abandonar la idea de que la fotografía es un espejo, una representación fiel de lo real.

Las mesas temáticas se organizaron en torno a premisas como "Medios Alternativos"; "La modernidad en la fotografía latinoamericana"; "Nuevas referencias históricas en Latinoamérica: Pasado"; "Nuevas referencias históricas en Latinoamérica: Presente"; "La experiencia de la transterritorialidad"; "Tendencias y alternativas de la fotografía documental”; entre otras. 
Si se observan en detalle los títulos de las mesas de debate, no solo pueden deducirse los temas abordados en el coloquio, sino también los cambios respecto a los encuentros anteriores.

Los debates giran en torno a nuevas cuestiones, que abren el campo para pensar la fotografía realizada en América Latina desde nuevos ángulos, marcando una diferencia entre el pasado y el presente. El nuevo orden mundial y la globalización llevan a incorporar autores $\mathrm{y}$ visiones internacionales para volver a pensar los discursos que sirvieron para la reflexión de la fotografía latinoamericana hasta el momento. Se hace evidente, asimismo, la necesidad de reflexionar sobre los cambios en las prácticas fotográficas con las tecnologías digitales y los nuevos medios de comunicación.

\section{Del documentalismo a la imagen construida}

A partir de lo desarrollado anteriormente, pueden señalarse dos aspectos importantes de las exposiciones y ponencias presentadas en los tres primeros coloquios. En primer lugar, el interés por pensar a la fotografía latinoamericana desde una perspectiva propia y en relación con los complejos contextos sociales, culturales, económicos y políticos de Latinoamérica como una unidad, resaltando las similitudes de las experiencias históricas compartidas. En segundo lugar, la reivindicación del fotodocumentalismo de registro directo, sin intervenciones sobre las imágenes, en la que se ponía en el centro las cualidades técnicas del dispositivo fotográfico para la representación fiel de lo real, lo que llevó a una reafirmación de la fotografía como testimonio y documento.

Se trata de una concepción de la fotografía que puede relacionarse a las teorías que, en el mismo contexto, intentaban definir la especificidad de la imagen fotográfica, poniendo en el centro la noción de dispositivo técnico y el concepto de lo fotográfico como objeto teórico, resaltando con ello el carácter icónico-indicial de la fotografía (Peirce, 1897/1987), el hecho de que la imagen resultante es una huella de lo que representa (Barthes, 1989/2005; Krauss, 1985/2002; Schaeffer, 1990; Dubois, 1990/2008).

Sumado a lo anterior, el auge que adquiere el uso de la categoría fotografía latinoamericana hacia fines de los años setenta puede relacionarse al lugar periférico del arte latinoamericano respecto al mundo del arte occidental (Danto, 2009) y su gusto por clasificar lo otro en términos geográficos y culturales (Mosquera, 2002). Este aspecto permite reflexionar sobre cómo en las ponencias y exhibiciones de los Coloquios antes mencionados se propone una definición de lo latinoamericano a partir de aspectos diferenciadores que sirven como autoafirmación cultural. Se exaltaba la localidad de producción, las coyunturas enunciativas y las particularidades histórico-sociales, revitalizando de esta manera el debate sobre las dependencias con los países centrales y la colonialidad. Es una postura que tiene sus antecedentes en las manifestaciones y discursos de ciertos artistas y movimientos artísticos latinoamericanos de la primera mitad del siglo XX, caracterizados, como explica Ivonne Pini (2000), por una búsqueda de lo propio como expresión de afirmación cultural y un modo de exaltar las especificidades latinoamericanas.

Esos dos factores deben ser pensados a la luz del contexto político internacional y latinoamericano entre los años 1960 y 1980: la Guerra Fría, los regímenes autoritarios que se sucedían en distintos países de la región, guerras en Centroamérica, la Revolución Cubana y la sandinista en Nicaragua, entre otros. Se trataba de un contexto en el que se revitalizó el espíritu de búsqueda de manifestaciones artísticas latinoamericanas que evidenciaran lo propio y criticaran las dependencias, en el que tuvieron lugar, como afirma Gerardo Mosquera (2002): el realismo mágico, lo real maravilloso, el mestizaje, el barroco, el afán constructivo, el discurso revolucionario, etcétera. Estas fueron categorias que 
sirvieron a los afanes de resistencia frente a la penetración cultural imperialista y en las que se planteaban "ciertas generalizaciones de la siempre deslizante identidad cultural latinoamericana” (p. 130).

A lo anterior se puede agregar la importancia que la idea de contexto adquirió en los discursos de los artistas latinoamericanos, categoría que servía como una marca diferenciadora, en términos de Richard (2007):

Para los márgenes y las periferias culturales, es decir, para aquellas otredades que se habian visto expulsadas del dominio autocentrado de la modernidad occidental dominante, fue vital reivindicar la diversidad del contexto, para combatir el universalismo y el imperialismo del valor. Contexto quiere decir aquí localidad de producción, sitio enunciativo, coyuntura de debate, particularidad histórico-social de una trama de intereses y luchas culturales que especifican el valor situacional y posicional de cada realización discursiva (p. 82).

En definitiva, se trata de una serie de factores que parecen haber llevado en un primer momento a categorizar a la fotografía latinoamericana como un conjunto de prácticas que giran en torno al documentalismo, en el que subyace la búsqueda de una autoafirmación a partir de la representación y el registro del contexto latinoamericano. Es una definición de la fotografía latinoamericana centrada en los significados más que en los significantes, más en la búsqueda de representar a América Latina desde su diferencia que en una reflexión de las prácticas artísticas y los lenguajes.

Esto se hace visible en las obras que integraron las exposiciones fotográficas de los tres primeros coloquios, en las que predominan los reportajes de tipo documental. Muchos fotógrafos latinoamericanos que alcanzaron visibilidad internacional, y fueron considerados referentes de la fotografía documental de la región, exhibieron sus imágenes en dichas exposiciones. Excede los alcances del presente artículo detallar todos los expositores de las muestras que integraron los coloquios, pero por nombrar algunos casos: Sara Facio, Eduardo Grossman y Juan Travnik (Argentina); Claudia Andujar, Boris Kossoy y Evandro Teixeira (Brasil); Gertjan Bartelsman (Colombia); Alberto Korda, Mario García Joya, María Eugenia Haya, y Raúl Corrales (Cuba); Graciela Iturbide, Lázaro Blanco, Lourdes Grobet, Flor Garduño, Mariana Yampolsky, Adrian Bodek, Alicia Ahumada, Pablo Ortiz Monasterio, Pedro Meyer, Rogelio Villareal y Nacho López (México); Sandra Eleta (Panamá); Roberto Fantozzi (Perú); Héctor Méndez Caratini (Puerto Rico); Antolín Sánchez (Venezuela); Diana Mines (Uruguay); entre otros. ${ }^{8}$

En contraste con lo anterior, en los años noventa es posible observar un cambio en la caracterización de la fotografía latinoamericana de la mano de críticos, teóricos y fotógrafos que planteaban que dicha categoría homogeneizaba bajo una misma rúbrica realidades dispares y diferenciales (Castellote, 2003), y resaltaba estereotipos: una América Latina rural y aislada, caracterizada por la violencia y la pobreza. Estas discontinuidades se pueden relacionar tanto al desarrollo de nuevos planteamientos curatoriales como a un contexto internacional marcado por los cambios en las prácticas fotográficas a partir del cuestionamiento del estatus de documento de la fotografía.

En efecto, la ruptura con el fotodocumentalismo puede ser considerada a la luz del debate más general que comenzó en los años noventa en torno a los impactos que las tecnologías digitales traerían en las prácticas fotográficas basadas en el soporte analógico. Fue un cambio en la naturaleza del dispositivo fotográfico que llevó a anunciar la muerte de la fotografía y la llegada a una nueva era: la de la posfotografía, a partir de la cual la fotografía se liberaría del binomio documental-ficción (Dubois, 2017; Fontcuberta, 2016; Green, 2007). 
Desde los años noventa curadores y críticos han expresado la necesidad de reconocer la heterogeneidad de las prácticas fotográficas latinoamericanas, identificando en la fotografía contemporánea de la región temáticas recurrentes a las que resumen bajo las categorías de historia, memoria e identidad (Alonso, 2008). Entre ellos se puede ubicar al curador de la muestra Mapas abiertos. Fotografía Latinoamericana 1991-2002, Alejandro Castellote (2003), en la que propone:

Hacer un panorama de las propuestas surgidas a lo largo de la década de los noventa a partir de tres argumentos: "Rituales de identidad", "Escenarios" e "Historias alternativas", una especie de contenedores temáticos que permiten mostrar a algunos de los autores más reconocidos y a una nueva y extensa generación cuya obra se ha hecho visible en este período (p. 5).

De manera similar, el curador cubano Juan Antonio Molina (2005), profundizando en la cuestión de la ruptura con el documentalismo en la fotografía latinoamericana en la última década del siglo XX, señala:

Cualquier análisis suficientemente desprejuiciado de la fotografía contemporánea latinoamericana demostraría que mediante la fotografía no realista se están abriendo puertas alternativas para una relación entre los sujetos y la historia [...] estas relaciones alternativas con la historia se dan básicamente mediante la construcción de historias alternativas (p. 29).

En un sentido similar, Mathieu Corp (2018) plantea que desde los años noventa las exposiciones de fotografía latinoamericana presentan temáticas recurrentes en torno a las nociones de identidad, historia y memoria, produciendo imágenes que fomentan experiencias significantes del tiempo, articulando pasado y presente y manipulando la historicidad de las referencias intro- ducidas: "comprometerse en una búsqueda memorial e identitaria sería entonces el medio con el cual los artistas deconstruyen, para reconstruir a veces, esas representaciones de América Latina” (p. 336). Desde una perspectiva afín, Martínez (2008, p. 154) afirma: "Los comentarios se producen de manera más sutil y buscan corroer las bases de las siempre pesadas plataformas de la oficialidad, proponiendo ironías, generando relaciones alegóricas con los símbolos maltrechos de patria, nación y obediencia”.

Estos cambios se hacen evidentes en las muestras de los dos últimos Coloquios Latinoamericanos en los que se expusieron obras fotográficas que incorporan operaciones artísticas como la apropiación y alteración de archivos; la puesta en escena y el montaje; y la resignificación de prácticas fotográficas canónicas. En los Coloquios de 1993 y 1996 estas obras fueron ganando participación, y en ellos se exhibieron los trabajos de importantes fotógrafos latinoamericanos que en este período alcanzaron renombre internacional y se posicionaron como referentes de la fotografía de la región en el circuito del arte contemporáneo. Incluso es posible observar cómo muchos de los fotógrafos que se nombraron anteriormente como referentes de las prácticas documentales cambiaron los modos de producir sus obras a partir de nuevas propuestas estéticas y exposiciones con grandes puestas en escena, como es el caso de Claudia Andujar, Graciela Iturbide, Flor Garduño y el propio Pedro Meyer.

En el caso de Claudia Andujar, por ejemplo, en Hecho en Latinoamérica 1 (1978) presentó imágenes de su ensayo documental de las décadas de 1960 y 1970, realizado para la revista Realidade sobre la comunidad Yanomami de la Amazonia. Era una obra que reunía fotografías en blanco y negro de tomas directas, sin intervenciones, con nitidez en el enfoque y claridad compositiva. A partir de los años noventa, cambia la estética en su obra y da un giro hacia las prácticas intervencionistas contemporáneas. 
9:: El catálogo de la Muestra de Fotografía

Latinoamericana (1996) puede consultarse en ihttps://issuu.com/c imagen/docs/muestra-defotografia-latinoamerica

10:: La obra puede observarse en inttps://

tatianaparcero.com

$11::$ La obra puede observarse en ihttp://www. adrianacalatayud.net

12:: La obra puede consultarse en ihttp://

fotografica.mx/

fotografos/gerardo-suter

13:: La obra puede

observarse en ihttp://

www.resh.com.ar

14:: La obra puede observarse en ihttps:// www.marcoslopez.com,

15:: La obra puede consultarse en ihttp://

v1.zonezero.com/

exposiciones/fotografos/ chiriboga/chi8sp.html,

16:: La obra puede observarse en ihttps://www. milagrosdelatorre.comı
Trabajando nuevamente con los Yanomamis de la selva Amazónica, Andujar registra los rituales chamánicos y la cacería de la comunidad, generando en esta oportunidad una visualidad desconcertante, creada a través de la intervención de la luz, que le permite producir atmósferas complejas con las que busca reivindicar las prácticas culturales y religiosas que durante el período colonial habían sido negadas y prohibidas (Rigat, 2018; Castanheiras, 2014). En dicha obra, la autora se aleja del realismo fotográfico a través de la reutilización de las imágenes en blanco y negro de los Yanomamis de su propio archivo, a las que interviene con la superposición de luces y elementos de la naturaleza (como agua, plantas y rocas) en color.

Como se señaló anteriormente, en el Encuentro de Fotografía de Caracas (1993) y en la Muestra Fotográfica Latinoamericana $(1996)^{9}$ es posible observar un predomino de fotografías construidas, intervenidas, con nuevas propuestas expositivas, por nombrar algunos ejemplos: Marcos López y Res, (Argentina); Marta Pérez Bravo, Adriana Calatayud, Tatiana Parcero y Eduardo Suter (México); Lucía Chiriboga (Ecuador); Javier Silva Montiel y Milagros de la Torre (Perú); Nelson Garrido (Venezuela); entre otros.

Las obras de estos fotógrafos, utilizando distintas operaciones artísticas, han buscado representar la identidad latinoamericana desde la heterogeneidad y la complejidad de nuestras sociedades. En la Muestra de Fotografía Latinoamericana (1996), Tatiana Parcero presenta Cartografía interior (1996) ${ }^{10}$ y Adriana Calatayud, Desdoblamiento (1996), ${ }^{11}$ dos obras en las que ambas artistas, a través del retrato, el autorretrato y la superposición de imágenes, recuperan códices mayas y aztecas, mapas $\mathrm{y}$ antiguos diagramas de anatomía, a los que colocan simbólicamente tatuados en la piel. En aquellos años, Gerardo Suter exponía sus series Códices (1991), Cantos rituales (1994) y Geografía de la memoria (1995/96), ${ }^{12}$ en las que a través de la puesta en escena reconstruía rituales arcaicos y códices prehispánicos.
En aquel mismo contexto, el fotógrafo argentino Res presenta su obra: NECAH 1879. No Entregar Carhué Al Huinca (1996), ${ }^{13}$ en la que reproduce en dípticos las imágenes de la llamada Conquista del Desierto del fotógrafo Antonio Pozzo, mostrando la usurpación de tierras a los pueblos originarios; se apropia de los documentos iconográfico del pasado para crear una nueva imagen en el presente.

Desde la cita, y se podría decir que ironizando ciertas cuestiones de las propias prácticas fotográficas latinoamericanas, se puede ver la obra de Marcos López, que en aquellos años comienza su serie Pop Latino (1996) ${ }^{14}$ en la que representa los cambios ocurridos en América Latina en los noventa con el fuerte impacto de la implementación de las políticas económicas neoliberales sobre nuestras culturas. En esta serie, López propone una reflexión crítica e irónica sobre las prácticas de representación de la identidad latinoamericana, a través de la puesta en escena de nuestros mitos y estereotipos.

Lucía Chiriboga expone en estos años Tengel, el tamaño del tiempo (1998/99), ${ }^{15}$ en la que recupera imágenes precolombinas, mapas y fotografías de archivos generando collages que ponen en diálogo dichos elementos, a fin de problematizar la historia ecuatoriana y peruana en el conflicto por el control de las tierras desde tiempos precoloniales hasta las luchas campesinas de mediados del siglo XX.

También en la revisión y resignificación de los modos de representación del otro a través de la fotografía decimonónica, Milagros de la Torre presenta en aquellos años su obra Bajo el sol negro (1991-1993), ${ }^{16}$ en la cual resignifica una práctica común realizada por fotógrafos callejeros en la Ciudad del Cuzco a principios del siglo XX. Se trata de una vieja técnica que imprime una pátina de mercurio sobre la piel del retratado en la fotografía, con lo que se obtiene una copia en la que puede observarse una imagen retocada que muestra cierto aclaramiento 
de la piel del sujeto. De la Torre hace uso de la misma técnica, pero en este caso las fotografías son copiadas como negativos, es decir que no pasan al positivo y se presentan intervenidas con una emulsión rojiza. Es una serie de fotografías que pueden relacionarse a los conceptos de pureza de sangre, raza y color de la piel, como conjunto estructurador del orden social en la colonia que persiste en los imaginarios culturales latinoamericanos.

Los mencionados son solo algunos ejemplos, entre muchos otros, que ilustran el giro que se va produciendo en la fotografía latinoamericana hacia fines del siglo XX.

\section{Reflexiones finales}

Como se ha podido observar, las actas y memorias de los Coloquios Latinoamericanos de Fotografía (algunas de ellas publicadas por primera vez en los últimos años) son documentos importantes para analizar las producciones teóricas y visuales de la fotografía de la región en el devenir de los años setenta y noventa. Dichos coloquios situaron a la fotografía latinoamericana en el ámbito internacional, estableciendo premisas de producción que la diferenciaran a nivel mundial (Carreras, 2018; Corp, 2018), y propiciaron una reflexión crítica sobre la identidad visual de la fotografía realizada en América Latina.

De la lectura de las memorias se ha podido identificar que los fotógrafos de los años setenta y ochenta tenían como paradigma de la producción visual fotográfica al documentalismo de compromiso político (Rigat, 2018; Monroy Nasr, 2000; Castellanos, 2000; Zerwes y Costa, 2017; Santos, 2014). Con este registro buscaban representar los complejos contextos sociales, culturales, económicos y políticos de Latinoamérica, resaltando las similitudes de las experiencias históricas compartidas, en particular lo que refiere a la conquista; la experiencia colonial y sus continuidades; la constitución de los nacional; las dependencias a los países centrales y el imperialismo; los regímenes autoritarios del siglo XX, los movimientos revolucionarios y de liberación, entre otros.
En los años noventa se produce un cambio en estas conceptualizaciones de la mano de curadores, críticos de arte, fotógrafos e investigadores que planteaban que dicha caracterización era una noción reductora y homogeneizadora de la fotografía latinoamericana (Castellote, 2003; Corp, 2018), y que impulsaba una imagen de América Latina rural y aislada, caracterizada por la violencia y la pobreza. Como se ha visto, ya en el Encuentro de Fotografía de Caracas (1993) comienza a debatirse sobre la necesidad de incorporar prácticas más conceptuales y ampliar así los parámetros sobre los que se había definido a la fotografía latinoamericana.

Estos cambios pueden observarse en las exposiciones de la época, en las que es posible notar un número decreciente de trabajos de reportaje documental y una significativa participación de obras que rompen y cuestionan la concepción del registro directo de lo real, en las que se incorporan operaciones artísticas caracterizadas por la intervención de los autores, ya sea sobre el plano de la representación o sobre el plano de lo representado.

Es posible, entonces, afirmar que desde los años noventa, y bajo la denominación de fotografía latinoamericana, se ha buscado redefinir los paradigmas que se habían establecido desde la década del setenta en relación con las prácticas visuales de la fotografía de la región. Es un cambio que se ve reflejado tanto en los planteamientos curatoriales como en las temáticas abordadas en las ponencias de los encuentros de la época y en las obras fotográficas. Se trata, en definitiva, de nuevas prácticas fotográficas contemporáneas que problematizan a la fotografía documental, abriendo a formas de pensar las imágenes y la representación no ya como meros espejos, sino como construcciones sociales que constituyen nuestros imaginarios y a la vez están atravesadas por dichos imaginarios. 


\section{Referencias}

Alonso, R. (Ed.). (2008). No sabe / no contesta. Prácticas fotográficas contemporáneas desde América Latina. Buenos Aires, Argentina: Ediciones arte $\mathrm{x}$ arte.

Barthes, R. (2005). La cámara lúcida. Buenos Aires: Paidós. (Trabajo original publicado en 1989)

Benedetti, M. (1981). Comentarios. En Consejo Mexicano de Fotografía, Hecho en Latinoamérica 2. Segundo Coloquio Latinoamericano de Fotografía (pp. 67-70). México D. F., México: Consejo Mexicano de Fotografía.

Carreras, C. (Coord.). (2018). Los Coloquios Latinoamericanos de Fotografía y la construcción de paradigmas en torno a la fotografía latinoamericana". En Tercer Coloquio Latinoamericano de Fotografía (pp.13-27). Montevideo, Uruguay: CDF.

Castanheiras, R. (2014). Rupturas na fotografia documental brasileira: Claudia Andujar e a poética do (in)visivel. Discursos fotográficos, 10(16), 53-84.

Castellanos, A. (2000). Pasajeros en tránsito. La fotografía en los años ochenta. Revista Tierra Adentro, 105. (pp. 4-8) Recuperado dehttps:// www.tierraadentro.cultura.gob.mx/pdf/091-120/105.pdf

Castellote, A. (2003). Mapas abiertos: fotografía latinoamericana. Madrid, España: Lunwerg.

Cisneros Hernández, P. (2013). La identidad Viajera en la fotografía contemporánea latinoamericana: una deconstrucción de su construcción (Tesis doctoral). Universidad Autónoma de Madrid, España. Recuperado dehttps://repositorio.uam.es/handle/10486/662238

Consejo Mexicano de Fotografia. (1978). Hecho en Latinoamérica. Memorias del Primer Coloquio Latinoamericano de Fotografía. México D. F., México: Consejo Mexicano de Fotografía.

Corp, M. (2018). Experiencias del tiempo en la fotografía latinoamericana contemporánea. Revista Kaypunku, 4(1), 327-381.

Danto, A. (2009). Después del fin del arte. Barcelona, España: Paidós.

Dubois, P. (2008). El acto fotográfico y otros ensayos. Buenos Aires, Argentina: La Marca. (Trabajo original publicado en 1990)

Dubois, P. (2017). Da imagem-traço à imagem-ficção: o movimento das teorias da fotografia de 1980 aos nossos dias. Discursos Fotográfico, 13(22),31-51.

Facio, S. (1981). Investigación de la fotografía y colonialismo cultural en América Latina. En Consejo Mexicano de Fotografía, Hecho en Latinoamérica 2. Segundo Coloquio Latinoamericano de Fotografía (pp. 103-107). México D. F., México: Consejo Mexicano de Fotografia.
Figarella, M. (1993). Comentarios. En J. Navarrete (Comp.), Memorias. Encuentro de Fotografía Latinoamericana (pp. 18-20). Caracas, Venezuela: Consejo Nacional de la Cultura/Fundarte.

Fontcuberta, J. (2016). La furia de las imágenes. Notas sobre la postfotografía. Barcelona, España: Galaxia Gutenberg.

Fontcuberta (2000). El elogio del vampiro. En Consejo Nacional para la Cultura y las Artes y Centro de la Imagen, VColoquio Latinoamericano de Fotografía (pp. 21-23). México D. F., México: Centro de la Imagen. (Trabajo original publicado en 1996)

García Canclini, N. (1981). Fotografía e ideología: sus lugares comunes. En Consejo Mexicano de Fotografía, Hecho en Latinoamérica 2. Segundo Coloquio Latinoamericano de Fotografía (pp. 17-20). México D. F., México: Consejo Mexicano de Fotografía.

Garcia Canclini, N. (2018). Estética e imagen. En C. Carreras (Coord.), Tercer Coloquio Latinoamericano de Fotografía (pp. 149-162). Montevideo, Uruguay: CDF. (Trabajo original publicado en 1984)

García Joya, M. (1981). La posibilidad de acción de una fotografía comprometida dentro de las estructuras vigentes en América Latina". En Consejo Mexicano de Fotografía, Hecho en Latinoamérica 2. Segundo Coloquio Latinoamericano de Fotografía (pp. 57-62). México D. F., México: Consejo Mexicano de Fotografia.

González Flores, L. (2005). Fotografía mexicana contemporánea. Un modelo para armar. En I. Benitez(Ed.), Hacia otra historia del arte en México (pp.79-108). México D. F., México: Curare.

Green, D. (Ed.). (2007). ¿Qué ha sido de la fotografía?Barcelona, España: Gustavo Gili.

Grobet, L. (1981). Imágenes de miseria: folclor o denuncia. En Consejo Mexicano de Fotografia, Hecho en Latinoamérica 2. Segundo Coloquio Latinoamericano de Fotografía (pp. 81-84). México D. F., México: Consejo Mexicano de Fotografía.

Günter, R. (1981). La fotografía como instrumento de lucha. En Consejo Mexicano de Fotografía, Hecho en Latinoamérica 2. Segundo Coloquio Latinoamericano de Fotografía (pp. 43-47). México D. F., México: Consejo Mexicano de Fotografía.

Haya, M. E. (2018). Premisas para la investigación de la fotografía latinoamericana. En C. Carreras (Coord.), Tercer Coloquio Latinoamericano de Fotografía (pp. 123-138). Montevideo, Uruguay: CDF. (Trabajo original publicado en 1984)

Herrera Ysla, N. (1993). Fotografía ilimitada e inalcanzable. En J. Navarrete (Comp.), Memorias. Encuentro de Fotografía Latinoamericana (pp. 11-17). Caracas, Venezuela: Consejo Nacional de la Cultura/Fundarte. Kossoy, B. (2001). Fotografía e historia. Buenos Aires, Argentina: La Marca. 
Krauss, R. (2002). Lo fotográfico por una teoría de los desplazamientos. Bercelona, España: Gustavo Gili. (Trabajo original publicado en 1985)

Martínez, L. (2008). Aproximación a la fotografía en Latinoamérica. En R. Alonso (Ed.), No sabe / no contesta. Prácticas fotográficas contemporáneas desde América Latina (pp. 143-158). Buenos Aires, Argentina: Ediciones arte $x$ arte.

Mendoza, P. (2000). Presentación. En Consejo Nacional para la Cultura y las Artes y Centro de la Imagen, V Coloquio Latinoamericano de Fotografía (p. 9). México D. F., México: Centro de la Imagen. (Trabajo original publicado en 1996)

Meyer, P. (1978). Presentación. En Consejo Mexicano de Fotografía, Hecho en Latinoamérica. Primer Coloquio Latinoamericano de Fotografía (pp. 17-20). México D. F., México: Consejo Mexicano de Fotografía.

Meyer, P. (1981). Palabras de presentación. En Consejo Mexicano de Fotografia, Hecho en Latinoamérica 2. Segundo Coloquio Latinoamericano de Fotografía (pp. 9-12). México D. F., México: Consejo Mexicano de Fotografía.

Meyer, P. (2000). Tres carabelas rumbo al nuevo milenio. En Consejo Nacional para la Cultura y las Artes y Centro de la Imagen, V Coloquio Latinoamericano de Fotografía (pp. 15-20). México D. F., México: Centro de la Imagen. (Trabajo original publicado en 1996)

Meyer, P. (2018). ¿Para quién y para qué se fotografía? En C. Carreras (Coord.), Tercer Coloquio Latinoamericano de Fotografía (pp.109-121). Montevideo, Uruguay: CDF. (Trabajo original publicado en 1984)

Molina, J. A. (2005). La historia a contrapelo. Modelos visuales y teóricos para el análisis de la fotografía contemporánea en América Latina. Situaciones artisticas Latinoamericanas. Recuperado de https://issuu. com/juanmolina/docs/lahistoriaacontrapelo

Monroy Nasr, R. (2000). Gamas, facetas y recuadros del fotodocumentalismo en México. Revista Tierra Adentro, 105 (pp.19-24). Recuperado de https:// www.tierraadentro.cultura.gob.mx/pdf/091-120/105.pdf

Monsivais, C. (1981). Comentarios. En Consejo Mexicano de Fotografía, Hecho en Latinoamérica 2. Segundo Coloquio Latinoamericano de Fotografía (pp. 85-87). México D. F., México: Consejo Mexicano de Fotografía.

Mosquera, G. (2002). Caminar con el diablo. Textos sobre arte, internacioanlismo y culturas. Madrid, España: Exit Publicaciones.

Navarrete, J. A. (2017). Fotografiando en América Latina. Ensayos de crítica histórica. Montevideo, Uruguay: CDF.

Peirce, C. S. (1987). La ciencia semiótica. Buenos Aires, Argentina: Nueva Visión.(Trabajo original publicado en 1897)

Pini, I. (2000). En busca de lo propio. Inicios de la modernidad en el arte de Cuba, México, Uruguay y Colombia. Bogotá: Universidad Nacional de Colombia.
Richard, N. (2007). Fracturas de la memoria. Arte y pensamiento crítico. Buenos Aires, Argentina: Siglo XXI.

Rigat, L. (2018). Fotografía latinoamericana contemporánea: critica poscolonial y renovación de los lenguajes. El caso Brasil. Crítica Cultural, 13(2), 233-244. Recuperado de http://www.portaldeperiodicos.unisul.br/index.php/Critica_Cultural/article/view/6714

Rosler, M. (1981). Comentario. En Consejo Mexicano de Fotografia, Hecho en Latinoamérica 2. Segundo Coloquio Latinoamericano de Fotografía (pp. 48-53). México D. F., México: Consejo Mexicano de Fotografía.

Sampaio Barbosa, C. (2011). Balance historiográfico de la fotografía latinoamericana a partir de una perspectiva brasileña. Metodologías y ejes de análisis. Recuperado de https://www.ungs.edu.ar/cm/ uploaded_files/file/publicaciones/trama/sampaio.html

Santos, A. (2014). Sobre essa tal de fotografia latinoamericana: uma análise do processo de demarcação de uma suposta essência fotográfica latina. Revista Contracampo, 29(1), 153-168.

Schaeffer, J. M. (1990). La imagen precaria. Del dispositivo fotográfico. Madrid, España: Cátedra.

Tibol, R. (1978). Presentación. En Consejo Mexicano de Fotografía, Hecho en Latinoamérica. Primer Coloquio Latinoamericano de Fotografía (pp. 17-20). México D. F., México: Consejo Mexicano de Fotografía.

Tibol, R. (2018). Expresión de lo latinoamericano en la fotografía. En C. Carreras (Coord.), Tercer Coloquio Latinoamericano de Fotografía (pp. 73-84). Montevideo, Uruguay: CDF. (Trabajo original publicado en 1984)

Torres, I. (1993). Presentación. En J. Navarrete (Comp.), Memorias. Encuentro de Fotografía Latinoamericana (p. 3). Caracas, Venezuela: Consejo Nacional de la Cultura/Fundarte.

Villares Ferrer, M. (2016). Hecho en Latinoamérica: la invención de la Fotografía Latinoamericana. Sures, 7. Recuperado dehttps://revistas. unila.edu.br/sures/article/view/404

Villareal, R. (1981). Comentario. En Consejo Mexicano de Fotografía, Hecho en Latinoamérica 2. Segundo Coloquio Latinoamericano de Fotografía (pp. 63-66). México D. F., México: Consejo Mexicano de Fotografía.

Zerwes, E. (2016). A fotografia humanista e a construção de uma historiografia sobre a fotografia latino-americana. Passo Fundo: História: Debates e Tendências, 16(2), 314-327.

Zerwes, E., y Costa, E. (2017). Os Colóquios Latino-Americanos de Fotografia e a institucionalização de uma fotografia brasileira. REB. Revista de Estudios Brasileños, 4(8). Recuperado dehttp://www.revistas.usp. br/reb/article/view/139797
Contribución autoral a) Concepción y diseño del trabajo; b) Adquisición de datos; c) Análisis e interpretación de datos; d) Redacción del manuscrito; e) revisión crítica del manuscrito.

L. $R$ ha contribuido en $a, b, c, d, e$.

Editor responsable: Leandro Delgado 